\title{
O IPTU COMO INSTRUMENTO DE DESENVOLVIMENTO SUSTENTÁVEL DOS MUNICÍPIOS
}

\author{
Lívio Augusto de Carvalho Santos ${ }^{1}$
}

RESUMO: O presente artigo tem como objetivo identificar os mecanismos tributários aplicados na tributação do IPTU para promover o desenvolvimento sustentável dos municípios. O problema de pesquisa é: quais os mecanismos do IPTU podem promover o desenvolvimento sustentável dos municípios? A conclusão obtida foi que capacidade contributiva, progressividade e alíquotas diferentes em razão da localização e utilização dos imóveis promovem desenvolvimento econômico, pois reduzem os gastos públicos com a implementação de políticas públicas, reduzem as desigualdades sociais e promovem a proteção ao meio ambiente. A pesquisa desenvolvida foi qualitativa do tipo documental bibliográfica, o método de abordagem escolhido foi o dedutivo.

Palavras-chaves: Desenvolvimento Sustentável; Extrafiscalidade; IPTU; Tributação.

\section{IPTU AS A TOOL FOR SUSTAINABLE DEVELOPMENT OF MUNICIPALITIES}

ABSTRACT: This article aims to identify the tax mechanisms applied in the taxation of the IPTU to promote the sustainable development of municipalities. The research problem is: what mechanisms of the IPTU can promote the sustainable development of municipalities? The conclusion obtained was that contributing capacity, progressivity and different rates due to the location and use of real estate promote economic development, because they reduce public spending with the implementation of public policies, reduce social inequalities and promote the protection of the environment. The research developed was qualitative of the bibliographic documentary type, the approach method chosen was the deductive.

Keywords: Extrafiscality; Property Tax; Sustainable Development; Taxation.

\section{INTRODUÇÃO}

Hodiernamente, no Brasil, tem-se percebido vários tipos de comentários (nos meios de comunicação) acerca da crise econômica o que vem potencializando as desigualdades sociais provenientes da injusta distribuição de riquezas. Neste passo, a crise econômica está prejudicando o desenvolvimento econômico do país. Em resposta a tal crise, observam-se várias ações estatais com a intenção de estimular o crescimento econômico, geração de emprego e

\footnotetext{
${ }^{1}$ Doutorando em Direito da Universidade de Marília - UNIMAR. Mestre em Direito pela Universidade de Santa Cruz do Sul - UNISC. Advogado. Professor da Graduação e da Pós-Graduação em Direito no CESVALE - Centro de Ensino Superior do Vale do Parnaíba. Professor do Curso de Bacharelado em Direito da Faculdade do Piauí FAPI E-mail: liviosantosadvocacia@ hotmail.com; CV Lattes: <http://lattes.cnpq.br/4706563346290283>.
} 
diminuição da pobreza. Destaca-se, que o objetivo almejado pelo Estado ao implementar essas políticas não é apenas o crescimento econômico, mas na verdade almeja o desenvolvimento econômico.

Paralelamente, o Estado não deve abster-se de implementar políticas públicas para promoção da redução das desigualdades sociais e para a proteção do meio ambiente, considerando o dever constitucional este imposto pela carta magna.

Ocorre que o Estado também passa por uma crise financeira, tendo como indicador a escassez dos recursos públicos, sendo que tal fato dificulta a manutenção da sua estrutura, a continuidade dos serviços públicos e a execução de políticas públicas. Cumpri ressaltar, que o município é o ente federado que mais sofre com a crise financeira, considerando que além de possuir a menor parcela da competência tributária é o que mais recebe demandas da sociedade por estar mais próximo do cidadão.

Vale destacar, ainda, que o tributo é a principal fonte de receita do Estado sendo fundamental para a manutenção de sua estrutura e a realização de suas atividades, incluindo-se os deveres constitucionais.

Neste contexto, o Município tem a difícil missão de compatibilizar tributação, crescimento econômico e proteção ambiental. Dessa forma, surge a problemática: quais os mecanismos do IPTU podem promover o desenvolvimento sustentável dos municípios?

Portanto, o objetivo do presente artigo é demostrar quais os mecanismos tributários que Município pode utilizar para, a partir da tributação da propriedade urbana, promover o desenvolvimento sustentável.

Para o desenvolvimento do presente estudo, divide-se o trabalho em pontos basilares, quais sejam: os fundamentos do desenvolvimento sustentável, para compreender os diversos significados, delimitando-se a relação existente entre crescimento econômico, desenvolvimento econômico e desenvolvimento sustentável; o papel do Estado e a importância da extrafiscalidade para promoção do desenvolvimento sustentável a relação existente entre o modelo de Estado, a tributação e a justiça fiscal, para tanto será abordado a justiça fiscal no neoliberalismo; e o IPTU e o desenvolvimento sustentável do município.

Para a elaboração do presente artigo, a pesquisa desenvolvida foi qualitativa do tipo documental bibliográfica, o método de abordagem escolhido foi o dedutivo e como método de procedimento será adotado o método monográfico. 


\section{OS FUNDAMENTOS DO DESENVOLVIMENTO SUSTENTÁVEL}

Para densificação do desenvolvimento sustentável faz necessário entender a relação existente entre crescimento e desenvolvimento, bem como, a relação existente entre desenvolvimento econômico e desenvolvimento sustentável.

Ao tratar do conceito de crescimento econômico Matos e Rovella apontam Adam Smith como precursor da utilização deste termo, afirmando que tal conceito despontou em 1776 com a publicação da obra A Riqueza das Nações. Segundo os autores nesta obra Adam Smith analisa "a formação da riqueza de uma nação, raciocinando sobre o funcionamento dos mercados e a relação da expansão dos mesmos para ganhos de escala de produção, onde os custos médios seriam reduzidos e permitiriam gerar lucros". (MATOS; ROVELLA, 2015, p. 2)

Acrescentam, ainda, que segundo Adam Smith esses lucros trariam frutos para a sociedade, considerando que ampliariam a possibilidade de trabalho, incrementando a renda da população e levando a uma redistribuição da renda, mesmo que em longo prazo.

Neste sentido, na teoria de Adam Smith o crescimento econômico é ponto de partida para o desenvolvimento econômico, visto que somente depois de gerado lucro e com o transcurso do tempo seria possível a geração de emprego, o incremento da renda e a redistribuição de renda.

Schumpeter (1911) possui outra perspectiva do desenvolvimento, analisa a influencia da utilização de inovações tecnológicas na economia e na sociedade para concluir que o desenvolvimento econômico é alcançado através da utilização da tecnologia. Portanto, a diferença entre crescimento econômico e desenvolvimento na compreensão de Schumpeter consiste no fato de que o primeiro é sinônimo de simples expansão na economia, enquanto que o desenvolvimento só pode ser alcançado com a utilização de inovações tecnológicas no processo produtivo.

Nesse panorama, a distinção entre a teoria de Adam Smith e Schumpeter é que segundo o primeiro o desenvolvimento é fruto natural do crescimento econômico, enquanto o segundo sustenta que só é possível chegar no desenvolvimento com a utilização de inovações tecnológicas. 
Lembre-se que, apesar da divergência doutrinária entre os supracitados autores, coadunam com ideia de que o desenvolvimento econômico é reflexo apenas em fatores econômicos, sem levar em considerações variáveis sociais.

Para além da analise do desenvolvimento de forma estritamente econômica, Amartya Sen é pioneiro em incluir variáveis pessoais e sociais na analise do desenvolvimento. Neste sentido, Favaro Neto, citando Amartya Sem, afirma:

Em sua obra "Desenvolvimento como Liberdade" (1999), Amartya sai da bolha de economistas que versavam sobre o desenvolvimento econômico com os reflexos apenas em fatores como o PIB (Produto Interno Bruto), industrialização, renda per capita, mudanças sociais e os avanços tecnológicos. Mesmo reconhecendo a importância desses fatores, Amartya Sen é pioneiro em assimilar variáveis pessoais como contribuintes para um melhor desenvolvimento, relacionando a melhora de vida dos indivíduos com o fortalecimento de suas liberdades. (FAVARO NETO, 2018, p. 160)

Acrescenta, ainda, o autor que as variáveis sociais incluídas por Amartya Sen, são o avanço dos serviços de educação e saúde, dos direitos civis e das liberdades do indivíduo.

Na mesma linha de pensamento, Mary Lúcia Andrade Correia e Eduardo Rocha Dias (2016) sustentam que deve ser incluído na analise do desenvolvimento econômico o fator qualidade de vida decorrente do crescimento econômico. Assim, só haveria desenvolvimento se o crescimento econômico acarretar em melhoria da qualidade de vida.

Para chegar a essa conclusão, o ponto de partida foi a distinção entre crescimento econômico e desenvolvimento econômico e para realizar esta distinção utiliza dos ensinamentos de Nusdeo e Miller.

Portanto, a diferença entre desenvolvimento e crescimento na compreensão de Nusdeo (2005, p. 355) consiste no fato de que este último é apenas o crescimento da renda e do Produto Interno Bruto - PIB, no entanto, sem implicar ou trazer mudança estrutural mais profunda. Neste sentido, Miller (2007, p.6) acentua que o crescimento econômico normalmente é medido pela mudança percentual no Produto Interno Bruto de um país e corresponde aos bens e serviços produzidos por todas as empresas e organizações nacionais e estrangeiras nesse Estado. Ressalta, ainda, o autor que "as mudanças no crescimento econômico de um país por pessoa são medidas pelo PIB per capita: o PIB dividido pela população total no meio do ano". (CORREIA; DIAS, 2016, p. 67)

Adriano Carvalho de Oliveira ressalta como marco fundamental para a dissociação entre crescimento econômico e desenvolvimento econômico o surgimento do Relatório sobre o Desenvolvimento humano, passando o desenvolvimento econômico a ser analisado por outros valores além do valor puramente econômico. 
Essa mitigação do "desenvolvimento econômico" ganhou maior força em 1990, quando do surgimento do primeiro Relatório sobre o Desenvolvimento Humano, o panorama acerca do desenvolvimento passou então a tomar contornos completamente diferentes. $\mathrm{O}$ crescimento da economia passou então a tomar contornos completamente diferentes. O crescimento da economia passou a ser entendido por muitos analistas como um elemento, dentre vários outros, componente de um processo maior, já que seus resultados não se traduzem de forma automática em benefícios. Foi percebida a relevância em se refletir acerca da natureza do desenvolvimento que se almejava. Ficando patente, dessa forma, que as políticas de desenvolvimento deveriam ser estruturadas por valores que vão além daqueles estabelecidos pela dinâmica econômica. (OLIVEIRA, 2016, p. 111)

Superada a questão da distinção entre crescimento econômico e desenvolvimento econômico, faz-se necessário a conceituação de desenvolvimento sustentável. Para Tanto Morais e Zolet sustentam que o desenvolvimento sustentável faz parte de um modelo político que busca o ponto de equilíbrio entre a economia, sociedade e meio ambiente, afirmando que:

O desenvolvimento sustentável faz parte de um modelo político que prevê a integração entre economia, sociedade e meio ambiente. A ideia desse desenvolvimento se faz presente por meio de um complexo processo de crescimento equilibrado. Esse processo deve considerar na maior medida possível o interesse pelo crescimento harmônico nas diferentes relações constituídas pela sociedade. (Morais; Zolet, 2015, p. 117)

De outro lado, Karla Marques Pamplona, com fundamento nas doutrinas de Sachs (1993), Alier (1994) e Costa (2006), destaca que o desenvolvimento sustentável é fenômeno mais complexo do que apenas o equilíbrio entre economia, sociedade e meio ambiente, uma vez que existem várias dimensões de sustentabilidade, apontado as dimensões econômica, social, ecológica, espacial e cultural.

Complementa a referida autora que o desenvolvimento econômico é modelo político que tem por finalidade assegurar equidade social, eficiência econômica, proteção aos recursos naturais, distribuição igualitária de espaços territoriais e valorização do patrimônio cultural, tradições e aptidões sociais, econômicas e culturais.

Desse modo, o desenvolvimento econômico sustentável nos termos da doutrina em referência, deve assegurar: (i) a equidade social, ou seja, a construção de uma sociedade pautada no "ser" e que exija uma melhor distribuição do "ter" ou da renda; (ii) a eficiência econômica, determinando a alocação e a gestão mais eficiente dos recursos e um fluxo regular entre os investimentos privados e públicos; (iii) o uso racional e equilibrado dos recursos naturais, em especial, os não renováveis, mediante a limitação do uso de recursos naturais esgotáveis e diversificando o uso dos ecossistemas conforme finalidades sociais válidas; (iv) a distribuição igualitária de espaços territoriais, havendo 
equilíbrio na configuração urbano e rural; e (v) a busca de um desenvolvimento endógeno, em contramão ao movimento capitalista, valorizando o patrimônio sociocultural de cada localidade ou país, isto é, suas tradições e aptidões sociais, econômicas e culturais. (PAMPLONA, 2016, p. 174)

O desenvolvimento sustentável, portanto, trata-se de um movimento para o uso e aproveitamento dos recursos humanos e materiais de forma adequada, equilibrando as relações econômicas, sociais e ambientais.

\section{O PAPEL DO ESTADO E A IMPORTÂNCIA DA EXTRAFISCALIDADE NA PROMOÇÃO DO DESENVOLVIMENTO SUSTENTÁVEL}

Após a compreensão do desenvolvimento sustentável como fenômeno complexo e movimento político para o uso e aproveitamento dos recursos humanos e materiais de forma adequada, equilibrando as relações econômicas, sociais e ambientais, faz-se necessário compreender o papel do Estado na promoção do desenvolvimento sustentável e como ele pode utilizar da tributação, em especial da função extrafiscal dos tributos, para promover o desenvolvimento sustentável.

Segundo Morais e Zolet o Estado tem o dever de implementar políticas públicas que promovam o desenvolvimento sustentável, senão vejamos:

Os Estados têm o dever ou a responsabilidade primordial de formular e implementar políticas públicas e ações equilibradas que possibilitem práticas de desenvolvimento, especialmente, a partir da ideia contínua da melhoria das condições da vida em sociedade. Logo, o principal desafio dos Estados, em tempos de desenvolvimento excludente, é propor um conjunto de medidas políticas capazes de equilibrar as relações entre pobreza, desenvolvimento econômico e meio ambiente. (Morais; Zolet, 2015, p. 117)

No mesmo sentido, Maria de Fatima Ribeiro e Aldo Aranha de Castro, citando Gilberto Bercovici, sustentam:

Conforme destaca Gilberto Bercovici, o desenvolvimento é condição necessária para o bem-estar social, sendo o Estado seu principal condutor por meio de programas e ações, o qual envolve a ampliação de oportunidades individuais e coletivas geradas pelo crescimento econômico, pela observância de valores fundamentais balizados constitucionalmente, como a justiça e a redução da pobreza e das desigualdades. (RIBEIRO; CASTRO, 2016, p. 7) 
Segundo Leonardo Maia Nascimento (2016) a Constituição Federal positivou o direito ao desenvolvimento sustentável, exigindo uma postura conjunta da sociedade civil e do poder público para preservação e proteção do meio ambiente equilibrado, inclusive atribuindo um instrumental ao poder público para cumprir essa atribuição. Assim, o Estado deve se utilizar de todos os instrumentos que lhe foram conferidos, inclusive seus agentes e a intervenção na esfera privada.

Após destacado o papel do Estado, temos que dentre os entes federativos o Município é o ente federativo que mais recebe demandas sociais, em razão de sua proximidade com os cidadãos, devendo se preocupar com em atender as demandas, sem prejudicar suas finanças.

Sobre o papel do Munícipio e os seus gastos públicos Rocha e Keske (2017, p.240) afirmam:

\footnotetext{
Quando o Município foi acolhido pelo federalismo, avançou de forma expressiva, e assim a participação de tal ente foi ampliada, com relação a execução de gastos públicos, sobretudo em ações sociais fundamentais. A esfera municipal passa a ser vista como local preferencial para a execução de políticas públicas, dirigidas especialmente à erradicação da pobreza, sobretudo pela possibilidade de um melhor controle do gasto público, visto que os governos locais têm uma menor propensão ao endividamento exagerado, com desequilíbrio das suas contas. (ROCHA; KESKE, 2017, 240)
}

Nesta esteira, destaca-se que todas as ações estatais com o objetivo de promover o desenvolvimento sustentável acarretam custos para o Estado, sendo a tributação indispensável para a esta tarefa. Ocorre que ao adotar uma política tributária, não pode se abster de não prejudicar o mercado, bem como, pensar em como utilizar a tributação de forma a não aumentar as desigualdades sociais e de forma a proteger o meio ambiente.

Maria de Fatima e Aldo (2016, p.6) corroboram com tal entendimento, afirmando que "a política tributária deve ser proposta como instrumento para a correção de desequilíbrios da diminuição das desigualdades, do crescimento e do desenvolvimento econômico".

Sobre o papel da tributação na promoção do desenvolvimento sustentável, Leonardo Maia Nascimento leciona:

\footnotetext{
Ou seja, os tributos, que surgem como ferramentas indissociáveis da manutenção da máquina administrativa, também servem para induzir comportamentos na sociedade e, por isso, devem ser bem analisados ao se firmarem as Políticas Fiscais e a Política Ambiental, de modo a se equilibrar a arrecadação e promoção de condutas adequadas aos interesses da Administração de preservação e proteção ambiental, coibindo aquelas indesejadas. (NASCIMENTO, 2016, p. 33)
} 
Cumpri destacar, que conforme ensina Paulo de Barros Carvalho (1993) as funções fiscais e extrafiscais dos tributos não são puras, devendo conviver as duas funções de forma harmônica, ou seja, mesmo que um tributo tenha função primordialmente fiscal nada impede que o Estado adote uma politica fiscal para que este tributo que tem por finalidade arrecadar também induza a prática de determinados atos desejáveis ou a abstenção da prática de atos reprováveis.

Neste passo, o Estado deve utilizar-se da função extrafiscal dos tributos para promover o desenvolvimento sustentável. Para melhor compreensão do tema faz-se necessário uma definição adequada da extrafiscalidade para posteriormente analisar as consequências/efeitos da utilização da extrafiscalidade no campo social e econômico.

Regina Costa, com supedâneo em Geraldo Ataliba, define a extrafiscalidaede como:

Consiste a extrafiscalidade no uso de instrumentos tributários para a obtenção de finalidades não arrecadatórias, mas estimulantes, indutoras ou coibidoras de comportamentos, tendo em vista outros fins, a realização de outros valores constitucionalmente consagrados. (COSTA, 2012, p. 75)

Com o objetivo de definir extrafiscalidade, Zilveti traça a diferença entre esta e a parafiscalidade a partir da teoria de Rubens Sousa, aduzindo que "a extrafiscalidade tem uma finalidade regulatória, enquanto a parafiscalidade tem o condão de custear atividades do Estado, no exercício do poder de polícia” (ZILVETI, 2004, p.191). Desta distinção, o doutrinador extrai que a extrafiscalidade é uma forma de classificação dos tributos em conformidade com a sua finalidade, destarte seriam tributos extrafiscais os que te finalidade de estimular ou desestimular condutas de acordo com a política de governo.

Conforme Nobre Júnior com a cobrança dos tributos extrafiscais o interesse não é só arrecadar, mas também perseguir "proveito que se manifesta através da correção de distorções sociais ou econômicas anormais" (NOBRE JÚNIOR, 2001, p. 95).

Silva teceu, a respeito, importantes observações:

A extrafiscalidade, pois, pode se manifestar pela majoração da carga tributária ou pela desoneração fiscal, entretanto, deve sempre desestimular qualquer comportamento que não busque a maior efetividade social dos direitos fundamentais e dos princípios constitucionais. (SILVA, 2010, p. 92) 
Quanto à extrafiscalidade manifestada através da majoração tributária, cabe ressaltar que sua finalidade não é arrecadar, mesmo que na sua aplicação acarrete o efetivo ingresso de recursos aos cofres públicos. A verdadeira função dessa maneira é "a realização do bem comum pela efetivação dos direitos fundamentais e, dos princípios constitucionais, pois a tributação representa um instrumento potencialmente eficaz à realização indireta dos direitos fundamentais". (SILVA, 2010, p. 95)

No que diz respeito à extrafiscalidade manifestada por meio da desoneração fiscal, Leão doutrina que esta pode ser implementa por meio de "isenções, benefícios fiscais, parcelamentos, progressividade ou regressividade de alíquotas" (LEÃO, 2015, p. 34), e afirma que a partir de distinções entre os atores econômicos tem o fito de atingir uma justiça físcal com desenvolvimento econômico equânime em todas as regiões da nação.

Ainda sobre extrafiscalidade manifestada por meio da desoneração fiscal, Silva vai além do entendimento apresentado por Leão, pois segundo ele, estes mecanismos de manifestação da extrafiscalidade além de ter "a finalidade de assegurar e estimular o desenvolvimento de determinada região ou de determinada atividade, de interesse comum” (SILVA, 2010, p. 93), também tem a finalidade de concretizar determinados direitos fundamentais.

Deste modo, para Silva a concretização de direitos fundamentais é objetivo almejado tanto na extrafiscalidade manejada pela majoração tributária quanto pela manejada pela desoneração fiscal, já o estimulo ao desenvolvimento de determinadas atividades ou regiões é objetivo almejado pela extrafiscalidade manejada pela desoneração fiscal.

Cabe ressaltar que na classificação que utiliza como critério a prevalência da função fiscal ou extrafiscal, este critério de classificação não é absoluto, pois, conforme esclarece Ricci (2015, p. 45) "por mais que determinadas espécies tenham maior aptidão fiscal ou extrafiscal, por exemplo, nenhuma espécie será pura”. Assim, mesmo que um tributo tenha função preponderantemente fiscal pode ser utilizado como ferramenta de implementação de políticas públicas, estimulando ou desestimulando determinadas condutas.

Do mesmo modo, Silva leciona que "qualquer imposição fiscal, trata- se de certa intervenção estatal, razão pela qual se pode afirmar que até mesmo os impostos que visam apenas arrecadar acabam tendo um certo grau de extrafiscalidade" (SILVA, 2010, p. 92).

Complementa Leão (2015) que os efeitos fiscais e extrafiscais podem conviver harmoniosamente na mesma norma, evidenciando que "os efeitos não fiscais dos tributos 
existem em maior ou menor grau na exação, independentemente se estes efeitos não fiscais foram ou não considerados quando da elaboração do enunciado normativo" (LEÃO, 2015, p. $34)$.

Portanto, o Estado deve se utilizar da natureza extrafiscal dos tributos para promover o crescimento econômico, a redução das desigualdades sociais e a proteção do meio ambiente.

\section{OS MECANISMOS DO IPTU E AS POLÍTICAS TRIBUTÁRIAS EXTRAFISCAIS}

Conforme se concluiu no tópico anterior o Estado tem o dever constitucional de promover o desenvolvimento sustentável devendo utilizar de todos os meios à sua disposição, sendo necessários recursos públicos que são capitados através da tributação. Neste passo a tributação é fundamental tanto pela função fỉscal, pois possibilita a ação estatal, quanto pela função extrafiscal que possibilita a indução de condutas desejáveis ou coibir as reprováveis.

O IPTU é uma das principais fontes de receita do município. Ao tratar do IPTU Leonardo Maia Nascimento, ressalta que embora tenha natureza fiscal ele também possui uma função extrafiscal relacionada ao cumprimento da função social da propriedade, bem como, que cabe a legislação do município estipular os critérios para o cumprimento da função social, incluindo entre essas a proteção ao meio ambiente.

\footnotetext{
A função do IPTU é tipicamente fiscal, entretanto ao se considerar o previsto no art. 182, §4, II, da Constituição Federal, tem-se entendimento diametralmente oposto, pois se apresenta o IPTU progressivo, com característica predominante de influir na conduta do contribuinte, ou seja, surge o IPTU com exacerbada função extrafiscal, função indutora, visa efetivar a função social do imóvel e que também pode se relacionar (conforme disponha a legislação) mais diretamente com a preservação e proteção do meio ambiente, quando considerado inadequado ou subutilizado o imóvel caso não atendidas as expectativas e metas fixadas na legislação. (NASCIMENTO, 2016, p. 39)
}

Neste passo, existem mecanismos tributários do IPTU que o Município pode se utilizar para induzir o comportamento da sociedade de forma a atingir determinadas finalidades almejadas pelo referido ente federativo, sendo eles: a capacidade contributiva, isenções, a progressividade, alíquotas diferentes em razão da localização e da utilização do imóvel.

No que diz respeito à capacidade contributiva é o instrumento mais eficaz para a redução das desigualdades sociais. Neste seguimento, Correia (2010) afirma que a utilização do tributo com o fim de reduzir as desigualdades sociais é oriundo da própria função social que é inerente 
ao tributo e acrescenta que deve ser um fim perseguido já que deve prevalecer o interesse social e a construção do comum.

\begin{abstract}
O tributo tem a função social de contribuir para com a ponderação das desigualdades sociais, de forma que os contribuintes recebam o retorno do Estado, em termos de serviços. Na verdade, os contribuinte es cooperam com o sacrifício de parte de seu patrimônio, na medida de sua capacidade contributiva, para que o interesse coletivo seja prestigiado, buscando-se a instauração de um clima de paz, segurança e prosperidade, do qual todos são beneficiados, mesmo aqueles que nada contribuíram, por serem "isentos", "imunes" ou não deterem capacidade para tanto. Desta forma, o tributo tem o condão de fazer prevalecer o interesse social sobre o interesse particular. (CORREIA, 2010, p.113)
\end{abstract}

Sustenta, ainda, a doutrinadora que não só o tributo tem o condão de reduzir as disparidades de distribuição como o Estado tem o dever de intervir no mercado econômico para promover esta maior equidade na distribuição da renda, mas isso só é possível se a tributação for aplicada de forma racional. Assim, "por meio da racional tributação é que podem ser diminuídas as distâncias que separam a minoria de pessoas que detém grande concentração de riqueza individual, e a maioria dos que não têm praticamente nenhuma riqueza particular" (CORREIA, 2010, p.113).

Na mesma linha de raciocínio, Silva (2010) afirma que somente com a aplicação do princípio da capacidade contributiva é possível a utilização da tributação com o intuito de promover a redução das desigualdades sociais, declarando que "se aplicado como parâmetro para majoração e instituição dos tributos, sempre que isto se fizer possível, é um grande instrumento contra a desigualdade social que, uma carga tributária mal dividida pode vir a gerar" (SILVA, 2010, p.116).

Baptista mesmo apontando críticas à eficácia e à avaliação da capacidade contributiva não refuta a ideia de que o princípio da capacidade contributiva é instrumento indispensável para a concretização da justiça fiscal, ao contrário, vai além, afirmando que além de justiça fiscal é possível alcançar a justiça social através do princípio da capacidade contributiva. Segundo Baptista (2007, p. 130) “tributando cada um na medida de suas possibilidades o princípio respeita a igualdade tão sonhada e perseguida. $\mathrm{O}$ valor arrecadado justamente retorna à sociedade sob a forma de investimentos para aqueles que são mais necessitados”. Destacando os investimentos na educação, cultura e informação. 
Ressalte-se, que tais investimentos são capazes de melhorar a vida das pessoas possibilitando igualdade de condições. Para tanto, além da arrecadação adequada respeitando a capacidade contributiva é necessário à alocação correta dos recursos arrecadados, promovendo a inclusão social. Neste sentido:

Com uma arrecadação na medida ideal e uma política sincera, esse valor poderia voltar a sociedade sob a forma de investimento na educação, cultura e informação das pessoas e melhora da vida delas redistribuindo e alocando devidamente os bens disponíveis na sociedade.

A alocação correta dos bens de produção e de consumo daria aos indivíduos componentes de nossa sociedade subsídios necessários para que haja uma igualdade de condições materiais (bens de produção de consumo) e imateriais (acesso a cultura, educação e lazer). (BAPTISTA, 2007, p. 131)

Acerca da distribuição dos bens na sociedade, Iatarola (2005) anuncia que esta distribuição dos bens na sociedade é denominada de princípio da diferença, tendo três pressupostos. O primeiro pressuposto é a distribuição no âmbito dos bens de forma a trazer um benefício maior para os mais desfavorecidos. O segundo pressuposto é a possibilidade de todos os indivíduos ocuparem posições e funções na sociedade. E por fim, o terceiro pressuposto é que os indivíduos tenham igualdade de oportunidades com condições mínimas de existência.

Deste modo, a aplicação de fato do princípio constitucional da capacidade contributiva num primeiro momento concretizaria da justiça fiscal, implicando numa igualdade econômica, porém, posteriormente, concretizaria a justiça social permitindo igualdade de oportunidades e inclusão social.

Quanto a progressividade, inicialmente, devemos compreender o sentido do termo "graduado" previsto no art. $145, \S 1^{\circ}$ da $\mathrm{CF}$, sendo que este termo "indica modulação, segundo alguma escala que permita tributar mais alguém e menos outrem” (Zilveti, 2004, p. 258).

Zilveti (2004) sustenta que existem vários critérios ou mecanismos para realizar esta modulação, tais como: proporcionalidade na qual as alíquotas são fixas, alíquotas variáveis em razão da progressividade, alíquotas diferentes em razão do uso ou do tipo do bem, alíquotas diferentes em razão da localização do bem e alíquotas diferentes em razão da essencialidade da atividade do contribuinte ou do produto. 
Destaca, ainda, o referido autor que todos esses critérios ou mecanismos devem estar em conformidade com o princípio da capacidade contributiva, sendo instrumentos de redistribuição de riqueza e consequentemente de realização da justiça fiscal e da justiça social.

Ainda sobre este tema Malheiros (2013) afirma que o princípio da capacidade contributiva é concretizado através da proporcionalidade, progressividade e seletividade, ou seja, a graduação dos impostos segundo a capacidade econômica prevista no art. $145, \S 1^{\circ}$ da CF é realizada através da proporcionalidade, progressividade e seletividade.

Aprofundando as noções firmadas, diferencia os três institutos, elucidando que a proporcionalidade é definida mediante "a aplicação de uma alíquota única sobre a matéria tributável variável, em que o imposto será proporcionalmente maior quanto maior for a matéria tributável, embora a alíquota permaneça sempre a mesma” (MALHEIROS, 2013, p. 81), de modo diverso, na progressividade "existe a variação da matéria tributável, bem como a variação da alíquota, sendo que esta última será maior quanto maior for o valor da matéria tributável" (MALHEIROS, 2013, p. 83), finaliza conceituando a seletividade como instrumento pelo qual a "carga tributária deve ser inversamente proporcional à essencialidade do produto, mercadoria ou serviço (MALHEIROS, 2013, p. 86), ou seja, as alíquotas deverão ser diferentes conforme a essencialidade dos bens ou produtos.

Vale ressaltar, que a Constituição impõe que o IPTU deve ter alíquotas progressivas em razão do valor do imóvel e do tempo.

Sacha Calmon (2015, p.234) aponta que essa progressividade não afronta a igualdade, caso em que haver tratamento diferenciado à pessoas que se encontram em situação de igualdade sem afrontar o princípio da igualdade, referindo-se, ainda à extrafiscalidade e ao poder de polícia.

A) a tributação exacerbada de certos consumos nocivos, tais como bebidas, fumo e cartas de baralho;

B) o imposto territorial progressivo para penalizar o ausentismo ou o latifúndio improdutivo;

C) o IPTU progressivo pelo número de lotes vagos ou pelo tempo, para evitar especulação imobiliária, à revelia do interesse comum contra a função social da propriedade;

D) imunidades, isenções, reduções, compensações para partejar o desenvolvimento de regiões mais atrasadas;

E) idem para incentivar as artes, a educação, a cultura, o esforço previdenciário particular (seguridade). 
A progressividade no tempo é associada ao cumprimento da função social da propriedade. Assim, um imóvel que não cumpri a sua função social deve ter uma alíquota de IPTU maior do que um imóvel que está cumprindo com função social. A aplicação deste instrumento tributário evita a manutenção de terrenos sem qualquer utilização dentro do município, evitando o crescimento desorganizado do município, ou seja, é instrumento de organização da zona urbana.

Destaca-se, que ao evitar o crescimento desordenado o município reduzirá os custos com algumas políticas públicas, considerando que o espaço geográfico em que deve investir é menor.

Quanto à utilização de alíquotas diferentes em razão da utilização e da localização, assim como o IPTU, também permite a ocupação adequada do solo urbano, permitindo a redução dos gastos públicos com políticas públicas.

Neste sentido, Faria (2016, p. 5) corrobora com o entendimento de que o IPTU pode ser utilizado como instrumento de política urbana, expondo que este imposto pode ser "utilizado como instrumento de política urbana e da consolidação da função social das cidades". Acrescenta, ainda, que deve ser utilizado o caráter extrafiscal do IPTU para atingir esse objetivo, lecionando que "nesse aspecto, tal tributo, utilizado em seu caráter extrafiscal, tem o condão de estimular e desestimular condutas, sem afetar a receita auferida com impostos, devido a previsão do art. 167, IV, CF" (FARIA, 2016, p. 5-6).

Cumpri destacar, ainda, que a adoção de medidas de responsabilidade e sustentabilidade ambiental com a finalidade de proteção ambiental estão incluídas na definição de função social da propriedade.

Segundo Faria a propriedade só está cumprindo a função social se preservar e proteger o meio ambiente.

\footnotetext{
A propriedade urbana estará cumprindo com sua função social, sempre que atender as exigências de ordenação das cidades, previstas no plano diretor. (art. 182, § $2^{\circ}, \mathrm{CF}$ ). Dentre tais determinações está a implantação de políticas de preservação e proteção ao meio ambiente, que garantam o bem-estar e a qualidade de vida da população. (FARIA, 2016, p. 6)
}

Portanto, por fazer parte da função social propriedade, o Município pode e deve atribuir alíquotas maiores para imóveis que não adotar medidas de prevenção e proteção ao meio ambiente e em contrapartida alíquotas menores para quem adotá-las. 


\section{CONSIDERAÇÕES FINAIS}

Percebe-se que o crescimento econômico, desenvolvimento econômico e desenvolvimento sustentável são distintos. Porém, não podemos negar que o desenvolvimento econômico e o desenvolvimento sustentável só são alcançados com o crescimento econômico.

Ao analisar o conceito de desenvolvimento sustentável evidencia-se que este está associado à utilização e aproveitamento dos recursos humanos e materiais de forma adequada, equilibrando as relações econômicas, sociais e ambientais.

Oportunamente, destaca-se o papel do Estado, em especial o papel do município em razão de estar mais próximo da sociedade, através da execução de políticas públicas, na promoção do desenvolvimento sustentável. Contudo não pode prejudicar suas finanças.

De fato, o Município necessita de recurso para a implementação de políticas públicas. Neste passo, considerando que o tributo é a principal fonte de receita, o Município tem que compatibilizar arrecadação com o crescimento econômico, a redução das desigualdades sociais e a proteção ao meio ambiente para promover o desenvolvimento sustentável.

Dentro dessa abordagem, a capacidade contributiva e a progressividade permitem a redução das desigualdades sociais, bem como a progressividade e as alíquotas diferentes em razão da localização e da utilização dos imóveis são instrumento de política urbana que permitem tanto a utilização eficiente de recursos públicos quanto a proteção ao meio ambiente.

A capacidade contributiva, isenções, a progressividade e alíquotas diferentes em razão da localização e da utilização do imóvel, possibilitam o equilíbrio entre a sociedade, economia e meio ambiente, reduzindo as desigualdades sócias, fomentando a atividade econômica e protegendo o meio ambiente, portanto são os principais mecanismos tributários que o município pode utilizar para promover o desenvolvimento sustentável.

\section{REFERÊNCIAS}

BAPTISTA, Hélio Daniel de Favare. Justiça tributária, justiça distributiva e solidariedade social: aplicação do princípio da capacidade contributiva. $139 \mathrm{f}$. Dissertação (Programa de Mestrado em Direito) - Centro Universitário de Marília, Marília, 2007.

CARVALHO, Paulo de Barros. Curso de direito tributário. São Paulo: Saraiva, 1993. 
COÊLHO, Sacha Calmon Navarro. Curso de direito tributário brasileiro. 14. ed. Rio de Janeiro: Forense, 2015.

COSTA, Regina Helena. Princípio da capacidade contributiva. 4. ed. São Paulo: Malheiros, 2012.

CORREIA, Emanuelle Araújo. A efetividade dos incentivos fiscais ambientais por meio de políticas públicas para a redução das desigualdades regionais. $135 \mathrm{f}$. Dissertação (Mestrado em direito) - Universidade de Marília, Marilia, 2010.

CORREIA, Mary Lúcia Andrade; DIAS, Eduardo Rocha. Desenvolvimento sustentável, crescimento econômico e o princípio da solidariedade intergeracional na perspectiva da justiça ambiental. Planeta Amazônia. Macapá, n. 8, p. 63-80, 2016. Disponível em: https://periodicos.unifap.br/index.php/planeta/article/view/2412. Acesso em:

FAVARO NETO, Aércio. Desenvolvimento e Justiça pela ótica de Amartya Sem. Revista Juris UniToledo. Araçatuba, SP, v. 03, n. 01, 159-174, jan./mar. 2018. Disponível em: http://www.ojs.toledo.br/index.php/direito/article/view/2738/257. Acesso em: 02 janeiro 2019.

FARIA ,Ana Luisa Sousa. O IPTU como instrumento para o desenvolvimento sustentável. Disponível em: http://www.publicadireito.com.br/artigos/?cod=b0169350cd35566c. Acesso em: 02 janeiro 2019.

IATAROLA, Ana Cristina Silva. CAPACIDADE CONTRIBUTIVA Princípio norteador de justiça tributária e sua limitação pelos direitos fundamentais: mínimo existencial versus não confisco tributário. 151 f. Dissertação (Mestrado em Direito) - Universidade Gama Filho, Rio de Janeiro, 2005.

LEÃO, Celina Gontijo. ITR e IPTU: o contraste entre as finalidades sociais e a gestão praticada. 144 f. Dissertação (Mestrado em Gestão Pública e Sociedade) - Universidade Federal de Alfenas, Varginha, 2015.

MALHEIROS, Carolina Rocha. A progressividade no impostos (os princípios da igualdade e da capacidade contributiva) (perfil constitucional). 206 f. Dissertação (Programa de PósGraduação em Direito - Mestrado) - Pontifícia Universidade Católica de São Paulo, São Paulo, 2013.

MATOS, Richer de Andrade; ROVELLA, Syane Brandão Caribé. Do crescimento econômico ao Desenvolvimento Sustentável: Conceitos em evolução. Disponível em: http://www.opet.com.br/faculdade/revista-cc-adm/pdf/n3/DO-CRESCIMENTO-ECONOMICOAO-DESENVOLVIMENTO-SUSTENTAVEL-CONCEITOS-EM-EVOLUCAO.pdf

MORAIS, Fausto Santos de; ZOLET, Lucas Augusto da Silva. Liberdade e desenvolvimento sustentável: questões fundamentais na democracia contemporânea. Universitas JUS, v. 26, n. 2, p. 111-122. 2015. Disponível: https://www.publicacoesacademicas.uniceub.br/jus/article/viewFile/3527/2797. Acesso em: 02 janeiro 2019.

Rev. de Direito Tributário e Financeiro | e-ISSN: 2526-0138 | Evento Virtual | v. 6 | n. 1 | p. 102-118 | 
NASCIMENTO, Leonardo Maia. A tributação na preservação do meio ambiente e no desenvolvimento sustentável. In: MENDES NETO, João Paulo; TUPIASSU, Lise. Tributação, meio ambiente e desenvolvimento. São Paulo: Forense, 2016. p. 29-46.

NOBRE JÚNIOR, Edilson Pereira. Princípio constitucional da capacidade contributiva. Porto Alegre: Sergio Antonio Fabris Editor, 2001.

OLIVEIRA, Adriano Carvalho. ICMS ecológico enquanto politica desenvolvimentista a partir da conjugação das concepções de desenvolvimento adotadas por Amartya Sem e Ignacy Sachs. In: MENDES NETO, João Paulo; TUPIASSU, Lise. Tributação, meio ambiente e desenvolvimento. São Paulo: Forense, 2016. p. 99-126.

PAMPLONA, Karla Marques. Estado federativo brasileiro, transferências intergovernamentais e desenvolvimento sustentável. In: MENDES NETO, João Paulo; TUPIASSU, Lise. Tributação, meio ambiente e desenvolvimento. São Paulo: Forense, 2016. p. 157-199.

RIBEIRO, Maria de Fátima; CASTRO, Aldo Aranha de. Políticas públicas tributárias, desenvolvimento e crise econômica. Disponível em:

http://www.publicadireito.com.br/artigos/?cod=dc6a6489640ca02b. Acesso em: 02 janeiro 2019.

RICCI, Henrique Cavalheiro. Direito tributário ambiental e isonomia fiscal:

Extrafiscalidade, limitações, capacidade contributiva, proporcionalidade e seletividade. Curitiba: Juruá, 2015.

ROCHA; Claudine Rodembusch, KESKE; Henrique Alexander Grazzi. O uso extrafiscal do tributo para o desenvolvimento local e a inclusão social. In: VITA, J. B.a; MEIRA, L. A.; BORGES, A. de M. (Org.). Direito tributário e financeiro II. Florianópolis: CONPEDI, 2017. p. 232-248.

SCHUMPETER, Joseph A. (1911). A Teoria do Desenvolvimento Econômico. São Paulo: Abril Cultural, 1982.

SILVA, Bárbara Raquel de Azevedo da. O princípio da capacidade contributiva e sua relação com a (des)igualdade social. $121 \mathrm{f}$. Dissertação (Programa de Pós-Graduação em Direito Mestrado) - Universidade do Vale do Rio dos Sinos - UNISINOS, São Leopoldo, 2010.

ZILVETI, Fernando Aurelio. Princípios de direito tributário e a capacidade contributiva. São Paulo: Quartier Latin, 2004. 